\title{
1.13 Productive Structure \\ in the Neo-Kaleckian Model of Growth and Distribution: Simulations to the Brazilian Economy.
}

\author{
Danilo Spinola \\ spinola@merit.unu.edu
}

\begin{abstract}
This study has as its main objective to analyze the relationship between structural change, exchange rate devaluation, growth and income distribution in Brazil. I simulate the NeoKaleckian model of growth and distribution as designed by Cimoli, Lima \& Porcile (2016) to the short run, in which there are no restrictions to deficits on the Balance of Payments. This is a Post-Keynesian model with Schumpeterian and Latin American Structuralism ideas. The shocks in the model helps us to understand the impacts of structural change, wage level increases, and exchange rate devaluations in Brazilian economy. The model is calibrated using real data for 2011. The results indicate the dynamics of the model and allow us to analyze possible impacts of changes in the productive sector to growth and income distribution in Brazil.
\end{abstract}

\section{Introduction}

The importance of discussing alternative macroeconomic models is imposed in a period when the economic international crisis highlighted the failure of policies based on financial liberalism of the new economic consensus' models. The contractive policies after the crisis did not succeed in recovering the health of economic system. It is fundamental to think of theoretical alternatives to understand impacts of the increase in income inequality and the fragility of specialized productive structures. Among these alternatives, it can be mentioned the following ideas:

1) Societies are divided in classes. These ideas are seen in the Neo-Kaleckian approach as defined by Blecker (2002). According to this perspective, classes interact, having a specific behavior in the distributive conflict mechanism. The diversity and different rationalities of workers, capitalists, the State and external sector should define the patterns of income distribution and growth in an economy.

2) Technological dynamism and productive structure are central elements to observe the development trajectories. In this sense, the Schumpeterian perspective is rich to understand how innovation impacts the economic system. Changes in the dynamics of the system are then not only quantitative, but fundamentally qualitative with disruptive and pervasive patterns that incessantly modify the economic systems in an evolutionary path. 
3) Underdevelopment as a structural problem. The ECLAC (2010) and ECLAC (2012) documents discussed the need for developing countries to advance in an inclusive growth pattern in order to sustain a long term development.

These ideas are the central ones related to the simulations of the Cimoli, Lima \& Porcile (2016) to the short run, understanding the impacts of changes in macroeconomic parameters to the Brazilian economy in a comparative static framework. This is a Post-Keynesian model of growth and distribution that merges the Kaleckian perspective of income distribution with the understanding of an evolutionary productive structure.

\section{The model}

This model is briefly presented as defined by Cimoli, Lima \& Porcile (2016), based in Blecker (2002). The model consists of three agents: capitalists, workers and government. The external sector plays a passive role, only supplying capital and intermediate goods. I use the Kaleckian assumptions that capitalists earn profits and save all they earn. Workers earn wages and spend all in consumption. The role of the government is to set the nominal interest rate and the nominal exchange rate by buying or selling reserves. The model is thought to discuss the short and the long run, where differences are related to the sustainability of external deficits.

Initially, Firms have a Leontief supply function in which there is no substitution between the factors of production.

$$
Y=\min \left(a L, b M^{m}, v K\right)
$$

$Y$ is the output, $L$ the total labor, $M^{m}$ is the amount of foreign intermediate goods, $K$ is the capital stock and $u$ is the level of capacity utilization in the economic system. $a$ is the productivity of labor, $b$ is the productivity of foreign intermediate goods and $v$ is the productivity

of capital. This model accepts existence of degrees of monopoly, where firms have a mark-up factor $z$. Because of imperfect competition, the prices are set over the marginal cost as presented in the following equation:

(2) $P=z\left(\frac{W}{a}+\frac{P^{*} E}{b}\right)$

(3) $P k=k P+(1-k) P * E$ 
Where $P$ is the price level, $W$ is the nominal wage level, $P^{*}$ the foreign price level and $E$ the nominal exchange rate. Prices are set over the costs of wages and intermediate goods. The costs are weighted by the mark-up factor $z$. For equation (3) we have the composed level of prices determined by the weight of domestic supplied good plus domestic price level and external supplied good plus international price level.

In macroeconomic theory, the goods and labor markets equilibrium derives from the equation $Y=C+I+G+X-M$. The function consumption of the government, $G$, is considered as part of the function of private consumption $C$. From the vision of output from the demand side, the function that equilibrates the goods market will result in:

$$
P^{y} Y=P C+k P I+(1-k) P^{*} E I+P X-P^{*} E M
$$

In which $k$ is the domestic share in supply of capital goods, $C$ is function of aggregate consumption, $I$ is the function of investment, $X$ is the amount of exports and $M$ the amount of imports. $P^{y}$ is a weighted price index related to the GDP.

Working with these macroeconomics variables, it is possible to find the following equations for the macroeconomic variables:

$$
\begin{aligned}
& \text { (5) } C=\frac{W P}{L} \\
& \text { (6) } I=g K \\
& \text { (7) } X=x K
\end{aligned}
$$

The variable $C$ represents aggregate consumption, while $I$ is the investment, and $g$ the investment rate $I / K$. The parameter $x$ represents the exports per unit of capital as $X / K$. With algebraic manipulations, the expression for the goods market equilibrium is:

$$
\text { (8) } u v=\sigma u v+k g+x-\frac{q u v}{b}
$$

The variables investment rate $g$ and export per unit of capital $x$ can be thought as functions of some parameters. The investment rate function depends on the interest rate and the decision of capitalists and its expectations over an uncertain future as defined by Keynes (1936). It also depends on the on the level of excess capacity, as described by Steindl (1952) and implemented in the Neo-kaleckian framework by Bhaduri \& Marglin (1990). The functions are thought as having a linear relationship. 
(9) $g=\alpha+\beta u-\tau r$

(10) $x=h u^{*}+j q$

In equation (9), $\alpha$ represents the animal spirit of the capitalists as defined by Keynes (1936). $\beta$ is the response of the investment function to changes in the utilization rate, while $\tau$ is the response to the real interest rate $r$. In the equation (10), $u^{*}$ is the rate of capacity utilization of the stock of capital in global economy, $h$ represents the non-price competitiveness and $j$ is the response of exports to a rise in price of competitiveness.

Applying equation (9) and (10) in equation (8), it is possible to determine the level of equilibrium of the economy adjusted by the value of $u$ :

$$
u=\frac{1}{v}\left[\frac{\left(k(\alpha-\tau r)+h u^{*}+j q\right)}{1-\sigma-\left(\frac{k \beta}{v}\right)+\left(\frac{q}{b}\right)}\right]
$$

In the short run, this model is adjusted to equilibrium by the excess capacity level, in which the nominal exchange rate $(E)$ is fixed and exogenous. When the value of $u$ is decided, it is then possible to determine the variables of investment level and imports.

$$
\begin{aligned}
& I=(\alpha+\beta u-\tau r) * K \\
& M=\left(\frac{u v k}{b}+(1-k) I\right)
\end{aligned}
$$

Finally, we find the functions that will determine the share of each class in the total real income:

$$
\delta=\frac{P^{*} E M^{m}}{P Y}=\frac{P^{*} E}{P b}=\frac{q}{b}
$$

$$
\pi=\frac{P Y-W P-P^{*} E}{P Y}=\frac{z-1}{z}
$$




$$
\sigma=1-\delta-\pi
$$

$\sigma$ represents the share of the workers in total output, $\delta$ the share of foreign intermediate inputs and $\pi$ the share of profit-earners. The variable $q$ represents the real exchange rate. In equation (15), the second passage has not been explicit, but with algebraic manipulation we see that the share of profit-earners in total output does not rely on the share of workers and imported intermediate goods. It depends on the distributive conflict that can affect the (here exogenous) mark-up factor $z$.

Productivity parameters ( $a, b$ and $v$ ) and the parameters $j$ and $h$ are strongly related to the productive structure. $k$ is related to the degree of diversification, complexity and technological density while $h$ is related to the ability of a country to participate in fast growing markets.

The parameter $j$ has a higher level when a firm is knowledge intensive, as it can react swiftly and raise production when the exchange rate becomes more competitive. Parameters changes can be used as a proxy to measure the impacts of a structural change in growth and distribution to the short run. In this way, this model is linked with the works of ECLAC (2010), ECLAC (2012) and ECLAC (2014) in the way that it tries to analyze impacts of the productive structure over the income distribution and understand how the structure also can determine growth.

The parameter $a, b, v, j, h$ and $k$ will then be called structural change parameters, as they depend on the quality of the products, the level of production and the productivity of an economy.

\section{Simulation and dynamics of the model}

In this section I apply parameter shocks to observe changes to income distribution, output level, prices and excess capacity.

Table 1. Parameters of the model

\begin{tabular}{lrlr}
\hline$L$ & $101 \times 10^{6}$ & $z$ & 1.7 \\
$D K$ & $6,5 \times 10^{15}$ & $P^{*}$ & 100 \\
$i$ & 11.67 & $E$ & 1.67 \\
$a$ & 135.33 & $u^{*}$ & 0.775 \\
$b$ & 10.71 & $k$ & 0.68 \\
$v$ & 0.37 & $W$ & 12881 \\
& & $P^{y}$ & 155 \\
$g$ & 0.06 & & \\
$\alpha$ & 0.20 & $x$ & 0.0409
\end{tabular}




\begin{tabular}{rrrr}
$\beta$ & 0.000026 & $h$ & 0.0500 \\
$\tau$ & -0.000291 & $j$ & 0.0024 \\
\hline
\end{tabular}

The calculus of the parameters can be found on the Statistical Appendix.

The calibration in Table 1 is based on real data from the Penn World Tables (Feenstra, Inklaar, \& Timmer, 2015). A further explanation can be found in the annex. Prices are in index, and the value of capital stock $D K$ is measured in US dollars in 2005 prices and calculated as the quantity $K$ times its related prices $P^{k}$. The share of capital stock supplied by domestic firms is $k$, and the share supplied by the external sector is $1-k$.

The results of the simulation of the parameters found for Brazilian economy in 2011 can be observed in the Table 2, below:

Table 2. Results of the Model

\begin{tabular}{lrlr}
\hline$K$ & $4.19 \times 10^{12}$ & $u$ & 0.818 \\
$P$ & 188 & $\sigma$ & $50.54 \%$ \\
$P k$ & 181 & $q / b$ & $8.28 \%$ \\
$Y$ & $1.62 \times 10^{12}$ & $\pi$ & $41.18 \%$ \\
& & & \\
$C$ & $42.88 \%$ & $X$ & $10.60 \%$ \\
$I$ & $51.38 \%$ & $M$ & $4.86 \%$ \\
\hline
\end{tabular}

For 2011 in the Brazilian economy, the output of the model shows that the share of profits in the Brazilian GDP represents around $41 \%$ and the share of wages represent $50.5 \%$. These results are close to empirical values, as it is for the level of excess capacity. About $8 \%$ of the GDP is used to import intermediate goods. Price level is a very interesting variable as it shows how an economy with high mark-up, as the Brazilian economy, that has higher mark-up level than the world average, shows high domestic prices when compared to external prices times the nominal exchange rate $\left(P^{*} E=167\right)$.

\section{Simulation 1. Exchange Rate}

The first effect simulated in the model shocks the nominal exchange rate. The shocks apply values of $80 \%, 90 \%, 110 \%$ and $120 \%$ of the baseline level. I also simulated the effect for the exchange rate level of October/2013 $(E=2.22)$. The results show impact on the income distribution, on the level of production capacity and on prices. 
Table 3. Exchange rate changes

\begin{tabular}{lrrrrrr}
\hline$E$ & 1.34 & 1.50 & 1.67 & 1.84 & 2.00 & 2.22 \\
\hline$E(\%)$ & -20.00 & -10.00 & 0.00 & 10.00 & 20.00 & 32.93 \\
$P$ & & & & & & \\
$u$ & -2.82 & -1.41 & 0.00 & 1.41 & 2.82 & 4.64 \\
$Y$ & 0.86 & 0.84 & 0.82 & 0.80 & 0.78 & 0.76 \\
\hline
\end{tabular}

Devaluation has impacts on prices, affecting costs of intermediate imported goods. This increase in costs affects final prices weighted by the markup factor. It raises domestic prices and affects consumption, exports and domestic investment, reducing them. The result is a decrease in the product, a negative growth rate.

An increase in nominal exchange rate level affects the real exchange rate. However the price effect reduces the exchange rate. The final result depends on the parameters to define the final impact on the real exchange rate. In the case of Brazilian economy, the final result of a nominal devaluation increases the share of imported intermediate goods in the output. As the share of the capitalists is constant, depending only on the markup, this results in a loss in the workers' share.

Finally, all these changes affect the capacity utilization level in a way that devaluation reduces the level of utilization of the capital stock. This effect happens because demand reduces due to price and income distribution changes. The capitalists, when see a reduction in demand, lower the use of capacity utilization adjusting it to demand variations.

\section{Simulation 2. Mark-up}

The second simulation is related to changes in the power relation between classes. Changes in power distribution and in the market structure affect the mark-up factor $z$. This factor is calculated as the markup relation that measure prices over costs plus 1 .

Table 4. Mark-up changes

\begin{tabular}{lrrrrr}
\hline$z$ & 1.45 & 1.53 & 1.62 & 1.70 & 1.87 \\
\hline$z(\%)$ & -15.00 & -10.00 & -5.00 & 0.00 & 10.00 \\
& & & & & \\
$P$ & -15.00 & -10.00 & -5.00 & 0.00 & 10.00 \\
$u$ & 0.94 & 0.89 & 0.85 & 0.82 & 0.77
\end{tabular}




\begin{tabular}{rrrrrr}
$Y$ & 7.57 & 4.77 & 2.26 & 0.00 & -3.90 \\
\hline$z$ & & & & & \\
\hline & 1.45 & 1.53 & 1.62 & 1.70 & 1.87 \\
$\sigma$ & & & & & \\
$\delta$ & 59.46 & 56.16 & 53.20 & 50.54 & 45.95 \\
$\pi$ & 9.74 & 9.20 & 8.72 & 8.28 & 7.53 \\
\hline
\end{tabular}

An increase in the market power of profit-earners represented by the markup factor $(z)$ increase prices, as firms are then in a more oligopolistic situation. The increases in prices and markup have as a result an increase in the share of capitalists on GDP. Prices then affect the relation between share of workers and share of imported intermediate goods. The final result is a reduction in worker's share.

A reduction in the workers' income share reduces their consumption and then the final demand. The output is then reduced because of income distribution effects on macroeconomic variables $C, I$ and $X$, and effect of prices over imports through changes in the real exchange rate.

The adjustment effect on capacity utilization occurs when demand increases (or decreases). This happens because of a reduction (or increase) in the markup change the share of workers in the GDP through price. Increasing in prices reduces the real wages, reducing consumption. An increase (reduction) in the capacity utilization level then affect investment through a defensive effect as described in Steindl (1952). The firms increase investment when there is high $u$ to defend themselves from potential new entrees. It is important to mention that this result is valid because there is no balance of payments constraint in the model.

\section{Simulation 3. Nominal Wage}

Table 5. Wage changes

\begin{tabular}{|c|c|c|c|c|c|c|}
\hline$W$ & 4671 & 10305 & 11593 & 12881 & 14169 & 15457 \\
\hline$W(\%)$ & -63.74 & -20.00 & -10.00 & 0.00 & 10.00 & 20.00 \\
\hline$P$ & -54.77 & -17.18 & -8.59 & 0.00 & 8.59 & 17.18 \\
\hline$u$ & 0.61 & 0.77 & 0.80 & 0.82 & 0.84 & 0.85 \\
\hline$Y$ & -8.38 & -1.44 & -0.65 & 0.00 & 0.55 & 1.02 \\
\hline$W$ & 4671 & 10305 & 11593 & 12881 & 14169 & 15457 \\
\hline$\sigma$ & 40.51 & 48.82 & 49.76 & 50.54 & 51.20 & 51.76 \\
\hline
\end{tabular}




\begin{tabular}{rrrrrrr}
$\delta$ & 18.31 & 10.00 & 9.06 & 8.28 & 7.63 & 7.07 \\
$\pi$ & 41.18 & 41.18 & 41.18 & 41.18 & 41.18 & 41.18 \\
\hline
\end{tabular}

Increases in wages have positive impacts on growth, but at the cost of increasing prices. As wages are costs, an increase in costs weighted by the markup results in a relevant increase in prices. The firms pass the increases of costs to prices.

When the wages are higher, the share of workers in GDP increases, stimulating demand. This demand stimulus makes firms elevate their capacity utilization level, also stimulating investment.

\section{Simulation 4. Structural Change Parameters}

The simulations consist in changes in the domestic production of capital goods, the productivity of labor and capital, and the Animal Spirit of the capitalists.

\section{Simulation 4.1 Domestic Supply of Capital Goods}

This simulation analyzes impacts of changes in the variable $k$. It is relevant to say that changes in this variable do not affect the income distribution, only output and capacity utilization level.

\begin{tabular}{|c|c|c|c|c|c|}
\hline$k$ & 0.00 & 0.61 & 0.68 & 0.75 & 1.00 \\
\hline$k(\%)$ & -100.00 & -10.00 & 0.00 & 10.00 & 47.06 \\
\hline$u$ & 0.19 & 0.76 & 0.82 & 0.88 & 0.98 \\
\hline$Y$ & -9.96 & -1.00 & 0.00 & 1.00 & 4.69 \\
\hline
\end{tabular}

Higher internal supply of capital goods affects positively product and utilization capacity levels. When the supply of capital goods is all domestic, the capitalists' decision to make investments affects internal production, stimulating investments and reducing imports. On the other hand, when there are no domestic supplies of capital goods, inversions are reduced while imports increase, affecting negatively GDP. 


\section{Simulation 4.2 Productivity Parameters}

An increase in the labor productivity parameter $a$ affects the income distribution, prices, capacity utilization level and product. However, changes in the capital productivity only affect the level of capacity utilization.

Table 7 - Productivity Parameters

\begin{tabular}{lrrrrr}
\hline$a$ & 108.27 & 121.80 & 135.33 & 148.86 & 162.40 \\
\hline$a(\%)$ & -20.00 & -10.00 & 0.00 & 10.00 & 20.00 \\
& & & & & \\
$P$ & 21.48 & 9.55 & 0.00 & -7.81 & -14.32 \\
$u$ & 0.86 & 0.84 & 0.82 & 0.80 & 0.78 \\
\hline & & & & & \\
\hline$a$ & 108.27 & 121.80 & 135.33 & 148.86 & 162.40 \\
\hline & & & & & \\
$\sigma$ & 52.01 & 51.26 & 50.54 & 49.84 & 49.16 \\
$\delta$ & 6.82 & 7.56 & 8.28 & 8.98 & 9.67 \\
$\pi$ & 41.18 & 41.18 & 41.18 & 41.18 & 41.18 \\
\hline
\end{tabular}

Increases in the labor productivity slightly affect income distribution, increasing the share of imported intermediate goods and reducing the share of workers. These changes are caused by domestic price effects. As prices are determined by costs, an increase in the productivity of labor strongly reduce costs as all productivity increase goes to imports. The price reduction compensates partially the loss of wages in total GDP, and increases consumption. As the productivity increases, even with a rise in consumption, the capacity utilization level shows a reduction, negatively affecting investments. The final result is an increase in the product due to a rise in consumption but with reduced capacity utilization level.

\section{Simulation 4.3 Animal Spirit}

This section simulates change in the level of the variable animal spirit $\alpha$. This variable represents a subjective expectation of capitalists and their disposition to perform investments. 
Table 8 - Investment Elasticity

\begin{tabular}{lrrrrrr}
\hline$\alpha$ & -0.06 & 0.00 & 0.19 & 0.20 & 0.21 & 0.26 \\
\hline$\alpha(\%)$ & -129.18 & -100.00 & -5.00 & 0.00 & 5.00 & 28.75 \\
& & & & & & \\
$u$ & 0.00 & 0.18 & 0.79 & 0.82 & 0.85 & 1.00 \\
$Y$ & -66.86 & -51.76 & -2.59 & 0.00 & 2.59 & 14.88 \\
\hline
\end{tabular}

The variable animal spirit does not affect the share of profits or the share of imported goods, for this reason, it does not affect income distribution. However, changes in this variable increase investment and so the final output. The animal spirit also affect the level of capacity utilization as the mood of the capitalists determine how they are disposed to invest, so the demand side of the economy continues determining the final result. The effects of changes in this variable are very elastic though, being a central variable to define growth pattern in the short run.

\section{Conclusion}

The results of the model show that an increase in demand, as well as changes in income distribution, define the growth pattern. Reductions in the mark-up of the firms, increasing wages and increases in the productivity of labor are measures that stimulate consumption and elevate aggregate demand. Increases in the mood of the capitalists improve investment and increases in the elasticity of exports to the interest rate elevate exports, these measures also increase growth as increase in the productivity of imported intermediate goods. Changes on the productivity of capital and on the share of domestic supply of capital goods do not affect income distribution but increase growth. Capacity utilization level variable is the adjustment for this model.

What we can observe is that contractive policies that reduce demand such as a fiscal adjustments and exchange rate devaluation have a strong impact in the reduction of the GDP. On the other hand, policies that foster income distribution, consumption of domestic products and investment have a very important effect on growth. Expectations are also important, as the animal spirit of capitalists affect investment. These expectations are directly related to the level of demand - which is another very important argument against policies that aim to strongly reduce demand in order to raise expectations, the effect is the opposite.

An important discussion that has to be brought and is slightly discussed in the model is related to the quality of the productive structure, meaning productivity and its possibility to create and absorb technology - problems directly related to future long run simulations.

It is important to highlight again that this model is simulated for short run, where balance of payments is not in equilibrium. In a medium-long run it is not possible to a country to grow under restriction in the external sector, especially for Latin American countries that have 
historical problems with external constrains. In the long run model, the government adjusts the nominal exchange rate by intervening by buying or selling foreign reserves.

Future research will be focused in understanding the role of external sector in Brazilian economic structure, relating it to the financial dynamic and with the innovation and diffusion process of dynamic productive structures.

\section{Bibliography}

BHADURI, A.; MARGLIN, S. Unemployment and the real wage: the economic basis for contesting political ideologies. Cambridge journal of Economics, 1990, vol. 14, no 4, p. 375-93.

BLECKER, R. Distribution, demand and growth in Neo-Kaleckian macro-models. The economics of demand-led growth. Cheltenham, UK: Edward Elgar, 2002.

CIMOLI, M., LIMA, G. T., \& PORCILE, G. The production structure, exchange rate preferences and the short-run-Medium-run macrodynamics. Structural Change and Economic Dynamics, 37, 13-26. 2016.

DOSI, G.; FAGIOLO, G.; ROVENTINI, A. Schumpeter meeting Keynes: A policy-friendly model of endogenous growth and business cycles. Journal of Economic Dynamics and Control, v. 34, n. 9, p. 1748-1767, 2010.

ECLAC, U. N. The Time for Equality: Closing Gaps, Opening Trails. Santiago: UN ECLAC, 2010.

ECLAC, U. N. Structural Change for Equality. Santiago: UN ECLAC, 2012.

ECLAC, U. N. Pactos para la igualdad: Hacia un futuro sostenible. Santiago: UN ECLAC, 2014.

Feenstra, R. C., Inklaar, R., \& Timmer, M. P. (2015). The Next Generation of the Penn World Table. American Economic Review, 105, 3150-3182.

FURTADO, C. 1959. Formação Econômica do Brasil. $1^{\text {st }}$ ed. Rio de Janeiro, Fundo de Cultura. $4^{\text {st }}$ ed. São Paulo: Companhia Editora Nacional (1976).

KALECKI, M. Class struggle and the distribution of national income. In: Michal Kalecki (eds), Selected Essays on the Dynamics of the Capitalist Economy, 1933-1970, (Cambridge University Press, Cambridge, UK 1970 [1971]) 156-164. 1970

KEYNES, J. M. The general theory of employment, interest and money. New York: Harcourt, Brace, 1936. Print.

MARSHALL, Alfred. Principles of economics. Vol. 1. 1898.

PREBISCH, Raúl. Estudio económico de América Latina. Cinqüenta anos de pensamento na CEPAL, Rio de Janeiro: Record, 2000a, 1949.

SCHUMPETER, J. A. Capitalism, socialism and democracy. New York: Harper \& Row. 1962 
SPINOLA, D. S. Estrutura produtiva no modelo Neokaleckiano de crescimento e distribuição: simulações para a economia brasileira. UNICAMP, Instituto de Economia, Campinas, SP. 2014 Available at:

<http://www.bibliotecadigital.unicamp.br/document/?code=000927424>

STEINDL, J. Maturity and stagnation in American capitalism. Oxford: Blackwell, 1952. Print. 


\section{Methodological Notes}

The calibration process required some adjustments which are better described in the next section. Below is a list of parameters for Brazil in 2011 that have an empirical source.

\begin{tabular}{lrlr}
\multicolumn{5}{l}{ Table. Empirical Parameters } & \\
\hline$D Y$ & $1,810,140,875,000$ & $E$ & 1.673 \\
$L$ & $101,325,000$ & $i$ & 11.671 \\
$D K$ & $6,493,198,000,000$ & $u$ & 0.824 \\
$D C$ & $1,215,871,625,738$ & $u^{*}$ & 0.775 \\
$D I$ & $379,767,555,575$ & & \\
$D G$ & $318,403,779,913$ & DMm & 158131554 \\
$D X$ & $246,722,201,263$ & DMbk & 74332348.9 \\
$D M$ & $350,624,287,488$ & DMbcons & 62060498.9 \\
$P i$ & 137.855 & DMpetr & 56099886 \\
$P^{*}$ & 100 & & \\
\hline
\end{tabular}

(1) The variables preceded with a $D$ means that they are calculated in their value in US\$ 2005 prices.

(2) $D Y, D K, D C, D I, D G, D X, D M, L, P i$ and $E$ are variables found in the Penn World tables. DY represents the value of the output; DK the value of capital stock; $D C$ the value of consumption; $D I$ the value of investment; $D G$ the value of government consumption; $D X$ the value of exports; $D M$ the value of imports; $L$ is the total labor force and $P^{i}$ the index of internal prices, having external prices as the basis 100 .

(3) $P^{*}$ : The international Prices are considered as 100 - based on the United States of America prices for 2011.

(4) $i$ : The variable of nominal interest $i$ was measured by its average for 2011. Data source is the Brazilian Central Bank (BCB)

(5) $u$ : The variable capacity utilization level $u$ used has its source in the State of Sao Paulo Industry Federation (FIESP) to the month of July of 2011.

(6) $u^{*}$ : The source for variable of international capacity utilization level $u^{*}$ is the website of the Federal Reserve (FED) for the month of July of 2011.

(7) $D M^{b k}, D M^{m}, D M^{b c} \& D M^{\text {petr }}$ : The data source is the Brazilian ministry of economy website. $M^{b k}$ is the import of capital good, $M^{m}$ of intermediate goods, $M^{b c}$ of consumption goods and $M^{\text {petr }}$ is the import of petroleum.

\section{Calibration process}


(1) Cimoli, Lima \& Porcile (2016) model had as an assumption the fact that government spending was calculated as private spending. $D G$ was aggregated to $D C$. The consumption variable received then the empirical values of consumption and of government spending. $D C=1534275405650$.

(2) Another assumption of the model Cimoli, Lima \& Porcile (2016) is that there are only import of intermediate and capital goods. In order to make it plausible, first the value of $M^{\text {petr }}$ was aggregated in the value of intermediate goods. The share of intermediate goods in the imports was then calculated, $D M^{m}=214231439.7$. The rest of imports was calculated as capital goods $D M^{b k}=136392847.8$.

(3) To calculate the quantity of consumption and export, each value was divided by the internal prices. $C=\frac{D C}{P^{i}}$ and $X=\frac{D X}{P^{i}}$.

(4) The value of consumption is equal to the consumption of the workers. This happens because workers consumption all that they earn, then: $W=\frac{P^{i} C}{L}$.

(5) The quantity of capital stock was calculated as: $K=\frac{D K}{P^{k}}$.

(6) The quantity of imported goods can be calculated as $M=\frac{D M}{P * E}$. This function can be decomposed with a participation of intermediate and capital goods as: $M=M^{m}+M^{b k}$.

(7) The function of final goods can be written as $M^{b k}=(1-k) * I$

(8) The Investment function is written as $I=\frac{D I}{P^{k}}$ where $P^{k}=k P+(1-k) P * E$. Having the final goods function and Investment function it is then possible to find the values of $k$ and I.

(9) With $C, I, X$ and $M$, it is then possible to find the quantity of $Y . Y=C+k I+$ $(1-k) q I \mp X-q M$.

(10) The parameters productivities of labor, imported intermediate goods and capital were calculated from the production function as: $a=\frac{Y}{L}, b=\frac{Y}{M^{m}}$ and $v=\frac{Y}{u K}$. It was used to calculate $v$ the empirical value of the capacity utilization variable $u$.

(11) With the productivity parameters, the mark-up factor was calculated as $z=\frac{P}{\frac{W}{a}+\frac{P * E}{b}}$

(12) The value of the investment rate was calculated as $g=\frac{I}{K}$

(13) The export per capital was calculated as $x=\frac{X}{K}$ 
(14) In order to discover the parameters that involves the functions that determine the investment rate and export per capital units, $g=\alpha+\beta u-\tau r$ and $x=h u+j q$, it was used observances related to the 10 last years with data found in the PWT.

(15) To measure the parameter of the function $x$, it was used a regression.

In the case of the function $x$, the coefficients show significance, but the results showed a behavior seen on Brazilian economy. The situation where the prices of commodities highly increased gave pressure to the exchange rate at the same time that did not affect the quantity of exported goods.

(16) The final results of the parameters calculated for Brazilian economy with the methodology described above are:

Table. Parameters

\begin{tabular}{lrr}
\hline$C$ & $1129659011 a$ & 132.31152 \\
$I$ & $2583111194 b$ & 10.4682741 \\
$X$ & $1789726903 \mathrm{v}$ & 0.36838605 \\
$M$ & 2096032326 & \\
$M m$ & $1280675751 \mathrm{~g}$ & 0.05848698 \\
$M b k$ & $815356574.8 x$ & 0.04052312 \\
$Y$ & 13406464783 & \\
$K$ & $44165574956 \mathrm{~W}$ & 15142.121 \\
$\mathrm{k}$ & $0.684 \mathrm{q}$ & 1.239 \\
$1-k$ & $0.31145859 \mathrm{r}$ & 8.46616258 \\
\hline
\end{tabular}

These results were used as parameters to calibrate the model. However, some adjustments, explained in next section, were necessary in order to better understand the dynamics of the model.

\section{Adjustments}

The results of the parameters measured in the methodology section gave relevant information for the calibration of the model. Still, some parameters showed weird numbers. The value of the share of profits was higher than $80 \%$, totally unreal to the Brazilian economy. This happened because we over-valuated consumption with low markup. In order to make more reality to the model, some parameters were recalculated.

Firstly, the nominal wage endogenously found in the methodology was substituted by an empirical value. In The Brazilian Institute of Geography and Statistics (IBGE), to the year 2011, the value of wages was of RS\$ $1.792,61$, about 3.3x the minimum Wage level. Using the 
nominal exchange rate level to $2011, E=1.67$, the level of annual wages in US $\$$ are $W=$ 12881.03 .

The mark-up found in the model represent a very low level compared to the real one empirically measured to the Brazilian economy. The mark-up factor is then fixed in the level of $z=1.7$. We can find the level of $z$ using the equation: $\frac{z-1}{z}=\pi$. For the prices $P$, they were recalculated with the new Mark-up, the final result can be seen on the model.

A very important change was done with the parameters of the investment rate equation $g$. The parameter was adjusted in order to find the desired level of utilization capacity. As $\alpha$ is a variable that does not have a value on itself, changes in its value were made without loss to the comprehension of the model.

The empirical results showed an inverse relation between real exchange rate and export per unit of capital. This result is due to other factors that alter these variables, like commodity prices and Chinese demand. In order to solve these problems, as this relation could not be found in other papers, an elasticity level was exogenously given as an arbitrary level that could represent the impact of exchange rate devaluation on the exports per capital. The variables $j$ and $h$ were then adjusted. 